\title{
Numerical study of a solar desalination system by humidification-dehumidification
}

\author{
Sirine Saidi 1,3*, Rym Ben Radhia ${ }^{1,3}$, Brahim Benhamou ${ }^{2}$, Naima Nafiri ${ }^{2}$, Sadok Ben Jabrallah ${ }^{1,3}$ \\ ${ }^{1}$ Laboratory of Energy and Heat-Mass Transfer, Department of Physics, University of Tunis El Manar, 1060 Tunis, Tunisia \\ ${ }^{2}$ EnR2E, National Center Studies and Research on Water and Energy CNEREE \& LMFE, CNRST Associated Research Unit, \\ Faculty of Sciences Semlalia, Department of Physics, Cadi Ayyad University, Marrakech, Morocco \\ ${ }^{3}$ Faculty of Sciences of Bizerte, Department of Physics, University of Carthage, 7021 Bizerte, Tunisia
}

\begin{abstract}
The present work represents a numerical study of a solar desalination system that operates on the humidification-dehumidification (HDH) principle. This system consists essentially of a humidifier integrated into a solar collector and a tubular condenser. A mathematical model governing evaporation and condensation in the desalination unit has been elaborated. This model is based on energy and mass balances at the humidifier and the condenser. The work consists essentially of a parametric study to improve the desalination unit production installed at the faculty of sciences of Bizerte, Tunisia.
\end{abstract}

\section{Introduction}

Fresh water is a source of life. The problem of the soft water shortage of in the world is growing in scale because of worldwide demographic and industrial evolutions. Natural freshwater resources cannot meet the growing demand for water [1-3]. One of solutions that can contribute to increasing water potentialities is the desalination of sea or brackish water. Desalination by humidification-dehumidification $(\mathrm{HDH})$ is one of the well-known processes in water desalination. It has the advantage of separating evaporation and condensation surfaces. In addition, this process is reliable because of the low technology used, the simplicity of design and ability to be locally manufactured. This process is the most suitable solution for providing fresh water for some families or small groups in remote are where there is a lack of energy. The HDH desalination systems are mainly composed by solar air and water collectors, a humidifier and a dehumidifier.

Several numerical and experimental studies [4-11] have been devoted to study of this type of distiller. The $\mathrm{HDH}$ systems differ in the design of humidifiers and dehumidifiers, the nature and number of solar collectors used and the daily production.

We study in this work a humidificationdehumidification solar desalination unit that consists of a humidifier and a dehumidifier. The advantage of this system resides in integrating the humidifier into the solar collector to reduce the cost of the desalination system. In previous work [12-13], we studied experimentally the desalination unit in the city of Bizerte, Tunisia. We have noticed that the unit's yield is relatively limited. For this, we resorted to the numerical study of the desalination system. The objective is to optimize the unit production so that we can make the necessary improvements to the experimental setup.
This study focuses on numerical modeling of the desalination unit. The objectives are:

-Elaborate and solve a mathematical model for the humidifier and the dehumidifier.

-Conduct a parametric study to improve the production of the desalination unit.

\section{Description of the desalination unit}

The studied desalination unit (Figure 1) operates on the humidification-dehumidification principle. It is constituted by a solar evaporator which is a humidifier integrated in a solar collector and a tubular condenser which plays the role of the dehumidifier. The humidifier having parallelepiped shape of length $\mathrm{L}=2 \mathrm{~m}$, width $\mathrm{l}=1 \mathrm{~m}$ and height $b=0.12 \mathrm{~m}$. It consists essentially of a flat sheet metal plate. A water film trickles on the outer face of this plate thanks to a porous fabric. A glass cover is exposed to solar radiation playing the role of a solar collector. It is subject on the wooden frame allowing the passage of humid air to the condenser and preventing the loss of vapor. The humidifier is placed on a support making an angle with the horizontal. The dehumidifier of the desalination system is a tubular water condenser. It consists of 21 copper tubes of $0.5 \mathrm{~m}$ length and $12 \mathrm{~mm}$ diameter arranged in parallel using two steel tube plates. Three steel baffles to force the passage of humid air.

The operating principle of the system is explained by two main steps: the ascending air enters in the humidifier where it is in direct contact with the streaming water film. This air humidifies following the evaporation of the film subjected to solar radiation entering through the glass and becomes charged with the water vapor that will be condensed in the condenser. The condensate is collected using a recuperator which that is placed below the condenser, while the brine is recovered at the bottom of the

\footnotetext{
*orresponding author: sirine274@live.fr
} 
humidifier. The air circulates in the unit either by natural or forced flow. The forced air flow is conducted by a fan that operates in suction and is placed at the level of the condenser purge.

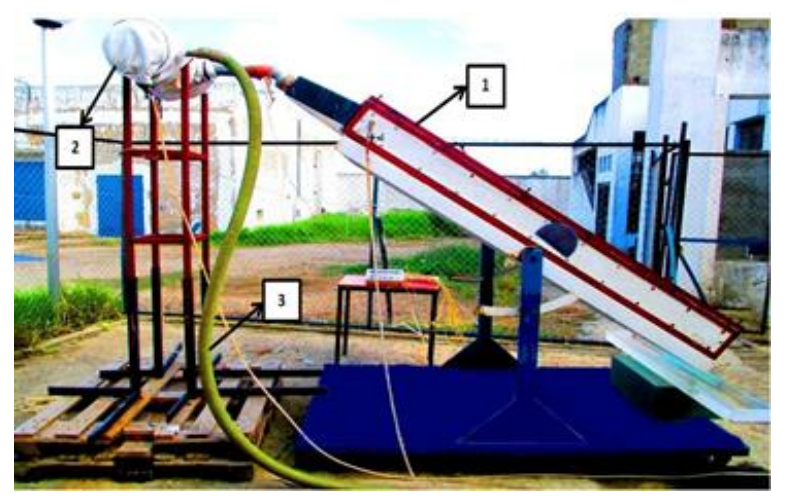

Fig. 1. A photograph of the desalination unit: 1- Humidifier; 2dehumidifier; 3- air suction conduit;

\section{Mathematical models}

\subsection{Mathematical model for humidifier}

In the humidifier, the air enters with a temperature $T_{g-L}$, a specific humidity $\omega_{1}$ and a mass flow rate $\dot{m}_{g}$. The liquid film is introduced with a temperature $T_{f-\text { hum }, 0}$ and a mass flow rate $\dot{m}_{f, 0}$. The airflow moves in parallel and counter-current with the falling liquid film. The modeling of the humidifier is done on a dx element (figure 2). We consider the positive direction from the top to the bottom of the humidifier.

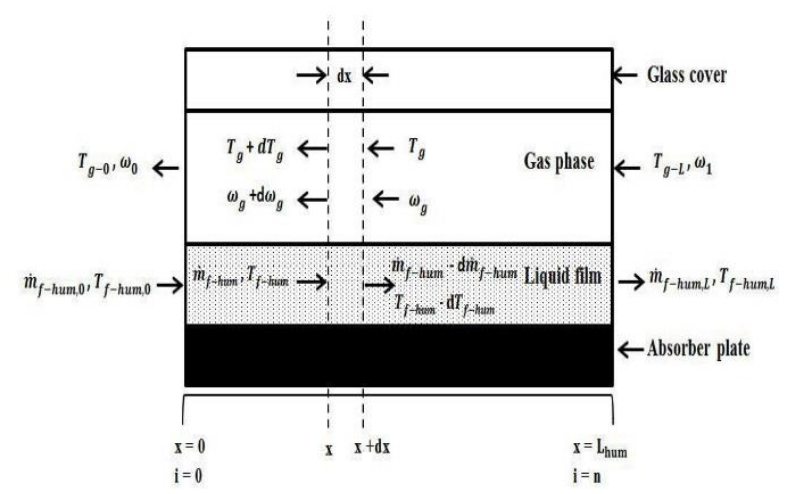

Fig. 2. An element of the humidifier

\subsubsection{Heat balances}

- Glass

$G S_{v} \alpha_{v}+h_{\text {int } / v-g} S_{v}\left(T_{g}-T_{v}\right)+\varepsilon_{g} \sigma S_{v}\left(T_{g}^{4}-T_{v}^{4}\right)=$ $\varepsilon_{v} \sigma S_{v}\left(T_{v}^{4}-T_{a}^{4}\right)+h_{\frac{\text { ext }}{v}-a i r} S_{v}\left(T_{v}-T_{a}\right)$

- Humid air

$$
\begin{aligned}
& -m_{g} C_{p, g}\left(\frac{d T_{g}}{d x}\right)+G l_{\text {hum }} \alpha_{v} \tau_{v}+ \\
& h^{\prime} l_{\text {hum }}\left(T_{g}-T_{f}\right)=\varepsilon_{v} \sigma l_{\text {hum }}\left(T_{g}^{4}-T_{v}^{4}\right)+ \\
& h_{\text {int } / v-g} l_{\text {hum }}\left(T_{g}-T_{v}\right)
\end{aligned}
$$

$$
\begin{aligned}
& \quad \dot{m}_{f} C_{p, f-h u m}\left(\frac{d T_{f-h u m}}{d x}\right)+G l_{\text {hum }} \alpha_{t}+\varepsilon_{p} \sigma l_{\text {hum }}\left(T_{p}^{4}-\right. \\
& \left.T_{f-h u m}^{4}\right)+h_{\text {int } p-f} l_{\text {hum }}\left(T_{p}-T_{f-h u m}\right)=\dot{m}_{g} \frac{d \omega_{g}}{d x} L_{v}+ \\
& h_{\text {intf-g }} l_{\text {hum }}\left(T_{f-h u m}-T_{g}\right)+\varepsilon_{\text {eff }} \sigma l_{\text {hum }}\left(T_{f-h u m}^{4}-\right. \\
& \left.T_{g}^{4}\right)
\end{aligned}
$$

- $\quad$ Plate

$$
\begin{aligned}
& \quad S_{p} \tau_{v} \alpha_{p} \tau_{f-\text { hum }} G=\varepsilon_{p} \sigma S_{p}\left(T_{p}^{4}-T_{f-h u m}^{4}\right)+ \\
& h_{\text {int } / p-f} S_{p}\left(T_{p}-T_{f-h u m}\right)
\end{aligned}
$$

\subsubsection{Mass balances}

$$
\begin{gathered}
\frac{d \dot{m}_{\text {evap }}}{d x}=\frac{d \dot{m}_{f}}{d x} \\
\frac{d \dot{m}_{\text {evap }}}{d x}=\dot{m}_{g} \frac{d \omega_{g}}{d x} \\
\dot{m}_{g} \frac{d \omega_{g}}{d x}=h_{m} l_{\text {hum }}\left(\left(\omega_{\text {sat }}\left(T_{\text {aver }}\right)-\omega_{g}\right)\right.
\end{gathered}
$$

Therefore, the solar evaporator model consists of seven spatial differential equations with seven unknowns. The main variables of the problem are then $T_{v}, T_{f-h u m}, T_{g}, T_{p}, \omega_{g}, \dot{m}_{f}$ and $\dot{m}_{\text {evap }}$.

\subsubsection{Boundary conditions}

- At $\mathrm{x}=0$

$$
\begin{array}{ll}
T_{f-\text { hum }}(0)=T_{f-\text { hum }, 0} ; & \dot{m}_{f-\text { hum }}(0)= \\
\dot{m}_{f-\text { hum }, 0} ; \dot{m}_{\text {evap }}(0)=0 & \text { (8) }
\end{array}
$$

$$
\begin{aligned}
& \text { - At } \mathrm{x}=\mathrm{L}_{\mathrm{hum}} \\
& T_{g}\left(\mathrm{~L}_{\mathrm{hum}}\right)=T_{g, L} ; \omega_{g}\left(\mathrm{~L}_{\mathrm{hum}}\right)=\omega_{1}
\end{aligned}
$$

Unknowns $T_{v}$ and $\mathrm{T}_{\mathrm{p}}$ do not need boundary conditions because they are not presented in differential form.

\subsection{Mathematical model for dehumidifier}

The studied dehumidifier consists of several identical tubes arranged parallelly. The air enters with a temperature $T_{h a-L}$, a specific humidity $\omega_{2}$ and a mass flow rate $\dot{m}_{h a}$. The cooling water is introduced at a temperature $T_{w-0}$ and a mass flow rate $\dot{m}_{w}$. The humid air flow in the dehumidifier (Figure 5) is counter-current with the water flow.

As the humid air progresses on the tube wall, the vapor condenses and instantly falls to the dehumidifier bottom. On the tube surface is a saturated vapor film where the phenomenon of condensation occurs. The film and the wall are taken at the same temperature $T_{f-d e h}$ (figure 3 ). We consider the positive direction from left to right. 


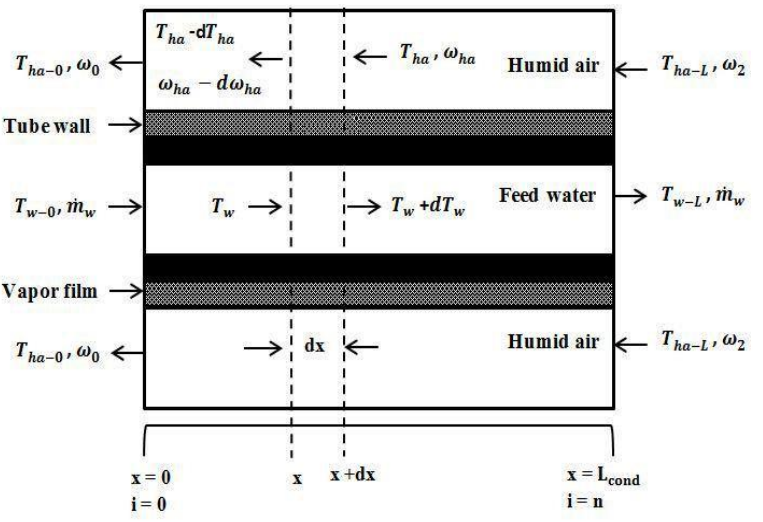

Fig. 3. An element of the dehumidifier

\subsubsection{Heat balances}

- Cooling water

$\dot{m}_{w} C p_{w} \frac{d T_{w}}{d x}=h_{w} \pi d_{i n t} N\left(T_{f-d e h}-T_{w}\right)+$

$\varepsilon_{f} \sigma \pi d_{\text {int }} N\left(T_{f-d e h}^{4}-T_{w}^{4}\right)$

- Vapor film

$\dot{m}_{h a} \frac{d \omega_{d e h}}{d x} L_{v}+h_{h a} \pi d_{e x t} N\left(T_{f-d e h}-T_{h a}\right)+$

$\varepsilon_{g} \sigma \pi d_{e x t} N\left(T_{f-d e h}^{4}-T_{h a}^{4}\right)=h_{w} \pi d_{i n t} N\left(T_{f-d e h}-T_{w}\right)$

Humid air

$\left(\dot{m}_{h a}\left(C p_{a}+\omega_{d e h} C p_{v a}\right)+\dot{m}_{c} C p_{c}\right) \frac{d T_{h a}}{d x}=$

$h_{h a} \pi d_{\text {ext }} N\left(T_{h a}-T_{f-d e h}\right)+\varepsilon_{g} \sigma \pi d_{e x t} N\left(T_{h a}^{4}-T_{f-d e h}^{4}\right)$

(12)

\subsubsection{Mass balances}

$\frac{d \dot{m}_{c}}{d x}=-\dot{m}_{h a} \frac{d \omega_{d e h}}{d x}$

$-\dot{m}_{h a} \frac{d \omega_{d e h}}{d x}=h_{m} \pi d_{e x t} N\left(\omega_{\text {deh }}-\omega_{s a t\left(T_{f-d e h}\right)}\right)$

The condenser model is composed of five differential space equations with five unknowns. The main variables of the problem are then $T_{e}, T_{f-d e h}, T_{h a}, \omega_{d e h}$ and $\dot{m}_{c}$.

\subsubsection{Boundary conditions}

- At $\mathrm{x}=0$
$T_{w}(0)=T_{w_{-} 0}$

- $\quad$ At $x=L_{\text {deh }}$

$$
\dot{m}_{c}\left(\mathrm{~L}_{\mathrm{deh}}\right)=0 ; \quad \omega_{\text {cond }}\left(\mathrm{L}_{\mathrm{deh}}\right)=
$$$$
\omega_{2} ; T_{a h}\left(\mathrm{~L}_{\mathrm{deh}}\right)=T_{h a_{-} L}
$$

The unknown $T_{f \text {-deh }}$ does not need boundary conditions because it is not presented in differential form.

\section{Resolution method}

The differential equations of the humidifier and dehumidifier presented above are not linear. The resolution must then be done iteratively in the form:

$$
\mathrm{A}^{-1} \mathrm{~d}=\mathrm{y}
$$

With

- A: matrix of coefficients

- d: Answer vector given by the boundary conditions

- y: Unknown vector

The resolution of the differential equations is performed by the Matlab numerical simulation software.

\section{Results and discussions}

\subsection{Validation}

In order to validate the calculation code, we compared the numerical and experimental results of the liquid film temperature along the evaporation plate. These two curves in natural (figure 4.a) and forced convection (figure 4.b) are traced during two days of almost typical summer days at $10 \mathrm{am}$. We selected two similar days in terms of weather conditions. The liquid film temperature profiles in the two convection modes have the same pace. Two zones are identified throughout the falling film: a first zone where the liquid film temperature increases which is a heating zone. A second zone where the film temperature decreases which is an evaporation zone.

An acceptable difference is observed between the two profiles for both convection modes. The maximum difference in the natural convection case is $8 \%$ whereas for forced convection, it is of the order of $9 \%$. 


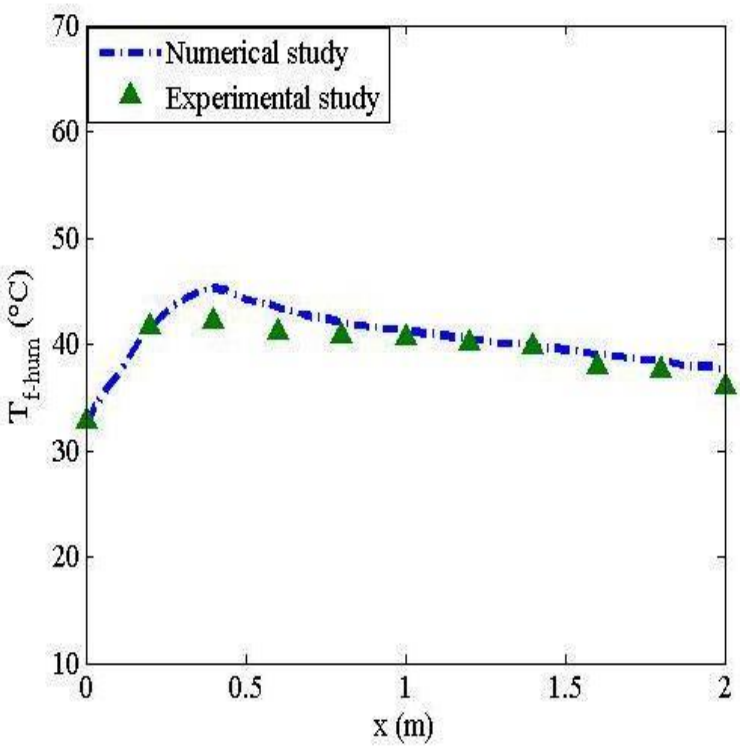

(a)

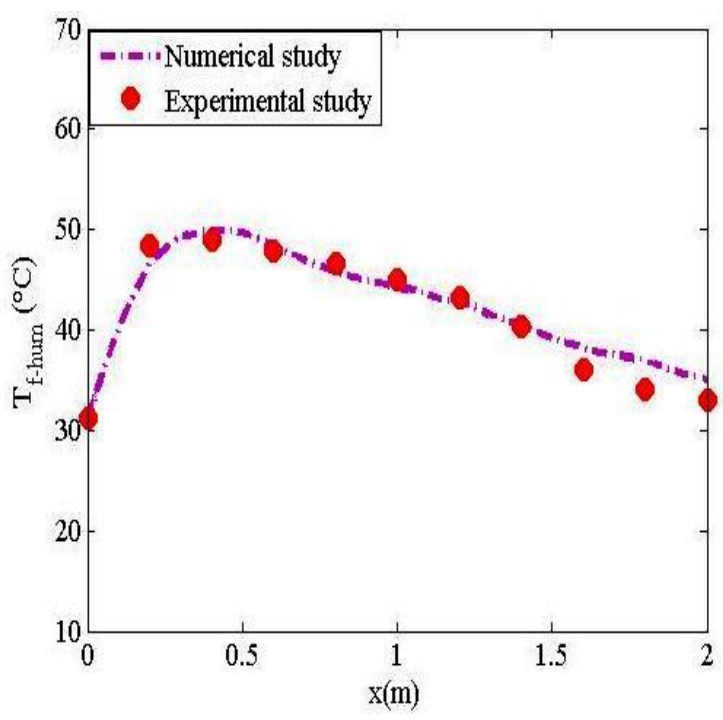

(b)

Fig. 4. Comparison between numerical and experimental results of liquid film temperatures along the humidifier in the natural (a) and forced (b) convection. (CN: $\mathrm{G}_{\mathrm{aver}}=766.1 \mathrm{~W} \cdot \mathrm{m}^{-2}$, $\left.\mathrm{T}_{\mathrm{amb}}=26-36^{\circ} \mathrm{C}, \mathrm{H}_{\mathrm{amb}}=45-59 \%, \dot{\mathrm{m}}_{\mathrm{f}-\mathrm{hum}}=4 \cdot 1 \mathrm{~kg} \cdot \mathrm{h}^{-1}\right) .\left(\mathrm{CF}: \mathrm{G}_{\mathrm{aver}}=\right.$ $770.7 \mathrm{~W} \cdot \mathrm{m}^{-2}, \mathrm{~T}_{\mathrm{amb}}=29-37^{\circ} \mathrm{C}, \mathrm{H}_{\mathrm{amb}}=45-55 \%, \dot{\mathrm{m}}_{\mathrm{f}-\mathrm{hum}}=4.1 \mathrm{~kg} \cdot \mathrm{h}^{-}$ $\left.{ }^{1}, \mathrm{~V}_{\mathrm{a}}=4.05 \mathrm{~m} \cdot \mathrm{s}^{-1}\right)$.

\subsection{Effect of feed water mass flow rate in the humidifier}

Figure 5 illustrates the influence of the feed water flow rate in the humidifier on the evaporated and condensed mass flow rates in forced convection. We note that the curve has two parts:

$-0<\dot{m}_{w}<0.001528 \mathrm{~kg} . \mathrm{s}^{-1}$ (whether $5.5 \mathrm{~kg} / \mathrm{h}$ ): the evaporated and condensed flow rates increases with the feed water mass flow rate. This result can be explained by the fact that for low mass flow rates the fabric that supports the film in the humidifier is not completely wet and still has dry areas. Hence the increase of $\mathrm{m}_{\mathrm{w}}$ promotes the uniform wetting of the fabric, hence the increase in the evaporated water mass flow rate.

$-m_{w}>0.001528 \mathrm{~kg} . \mathrm{s}^{-1}$ : The evaporated and condensed flow rates decreases with the feed water mass flow rate. This decrease can be explained, on the one hand, by the fact that increasing the mass flow rate in the humidifier requires greater energy to heat the liquid film. Thereafter, the solar flux consumed by the phase change decreases. On the other hand, when the feed water mass flow rate increases, the liquid passes too quickly into the humidifier and does not find enough time to warm up and evaporate.

The condensate mass flow rate thus varies in the same direction as the evaporated mass flow rate.

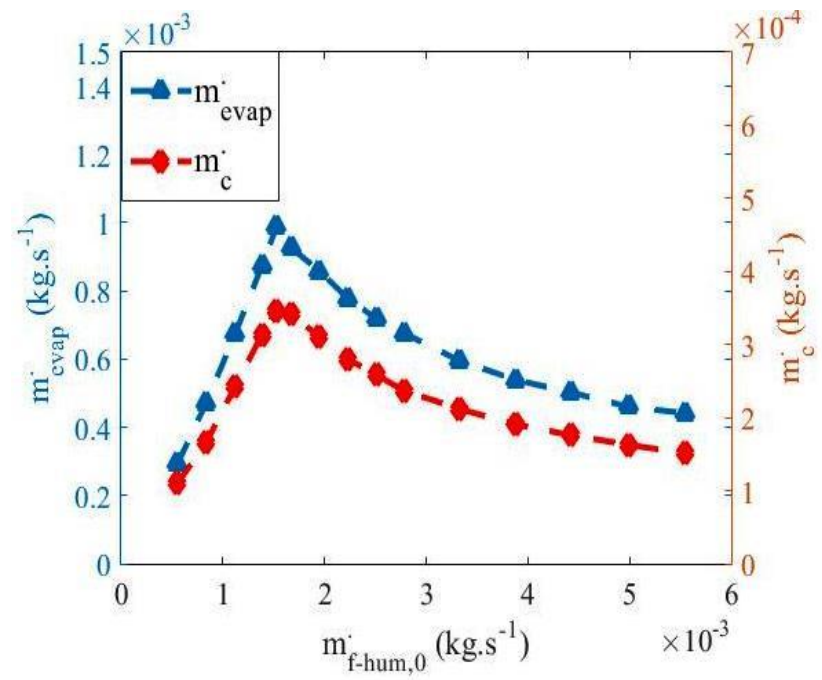

Fig. 5. Evolution of evaporated and condensed mass flow rate according to the feed water temperature at the humidifier $\left(T_{f-\text { hum }, 0}=30^{\circ} \mathrm{C}, T_{a, L}=35^{\circ} \mathrm{C}, \dot{m}_{a}=0,0147 \mathrm{~kg} . \mathrm{s}^{-}\right.$ $\left.1, T w_{-} 0=20^{\circ} \mathrm{C}, \dot{m}_{w}=0.035 \mathrm{~kg} \cdot \mathrm{s}^{-1}\right)$

\subsection{Effect of feed water temperature in the humidifier}

Figure 6 shows the variation of evaporated and condensed mass flow rate according to inlet feed water temperature at the humidifier in forced convection. Evaporated and condensed mass flow rates increase with the feed water temperature in the humidifier. Indeed, by increasing the feed water temperature, the amount of sensible heat necessary to water heat decreases. Therefore the solar radiation received by the liquid film dripping on the evaporator plate is used for evaporation. Improved evaporation then generates an increase in condensate mass flow rate. Therefore, the condensate mass flow rate increases with the heating of the water in the humidifier. 


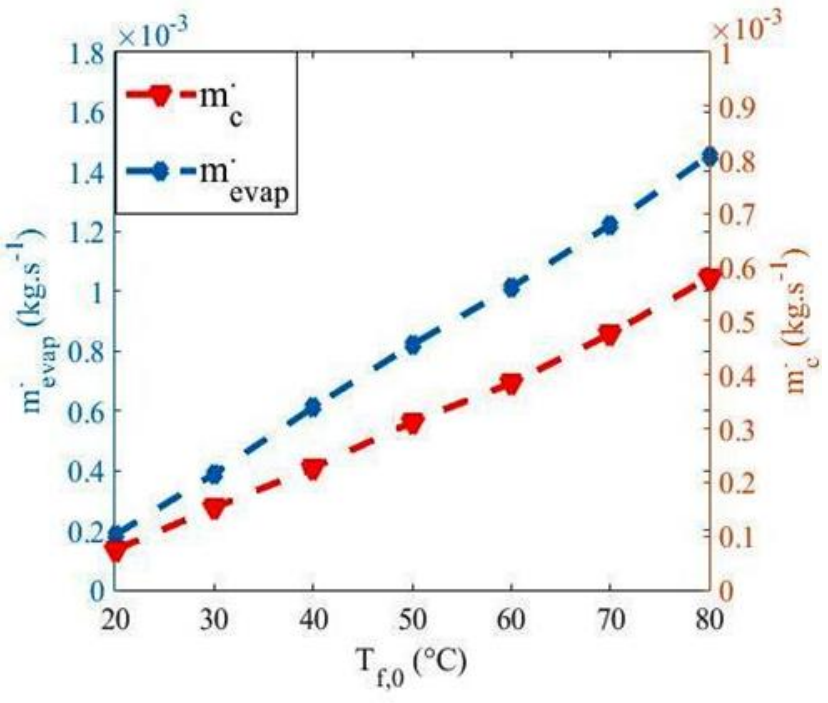

Fig. 6 Evolution of evaporated and condensed mass flow rates according to the feed water temperature in the humidifier. $\left(\dot{m}_{f, 0}=0.001528 \mathrm{~kg} \cdot \mathrm{s}^{-1} T_{a, L}=35^{\circ} \mathrm{C}, \quad\right.$ sec, $\quad \dot{m}_{a}=0,0147 \mathrm{~kg} \cdot \mathrm{s}^{-1}$, $\left.T e \_0=20^{\circ} \mathrm{C}, \dot{m}_{w}=0.035 \mathrm{~kg} . \mathrm{s}^{-1}\right)$

\subsection{Effect of inlet air temperature in the humidifier}

Figure 7 illustrates the influence of the inlet air temperature at the humidifier on the evaporated and condensed mass flow rates in forced convection. It is noted that the mass flow rates increase almost linearly with the air temperature. Indeed, by increasing the air temperature, on the one hand, an additional energy is added to the liquid film other than the solar irradiation and on the other hand, more the air temperature is high, more it can be charged with water vapor. Therefore, it can be concluded that increasing the air temperature improves evaporation. The increase in evaporated mass flow rate then generates an increase in the condensate mass flow rate.

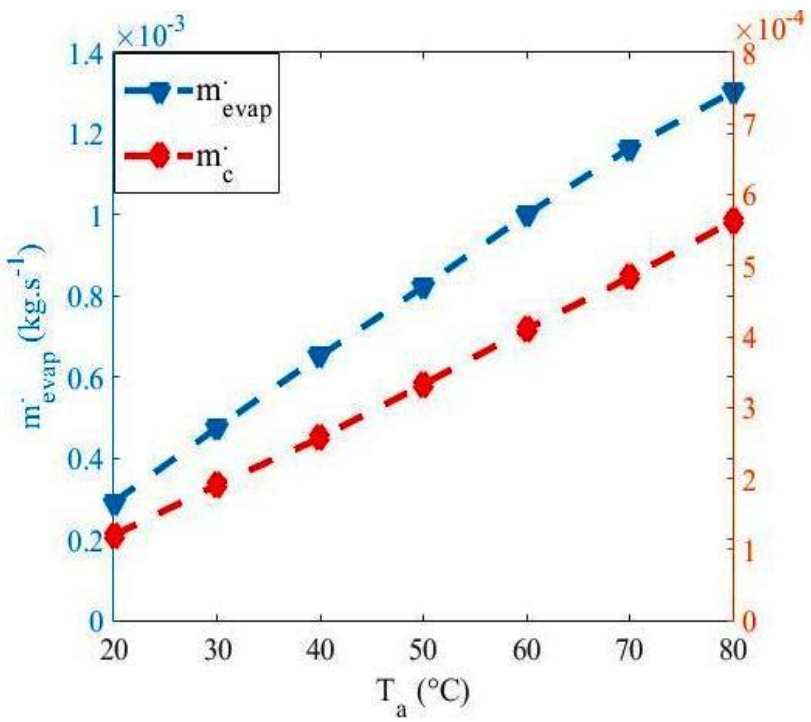

Fig. 7 Evolution of evaporated and condensed mass flow rate according the inlet air temperature at the humidifier $\left(T_{f}\right.$ hump, $0=40^{\circ} \mathrm{C}, \dot{m}_{f, 0}=0.001528 \mathrm{~kg} \cdot \mathrm{s}^{-1}, \mathrm{~kg}_{\text {vapeur }} / \mathrm{kg}_{\text {air }}, \dot{m}_{a}=0,0147$ kg. $\left.\mathrm{s}^{-1}, T w_{-} 0=20^{\circ} \mathrm{C}, \dot{m}_{w}=0.035 \mathrm{~kg} \cdot \mathrm{s}^{-1}\right)$

\subsection{Effect of the air humidity at the inlet of the humidifier}

Figure 8 shows the variation of the evaporated mass flow rate according to the air specific humidity at the inlet of the humidifier in forced convection. The evaporated flow rate decreases with increasing air humidity at the humidifier inlet. In fact, more the air humid at the humidifier inlet, more it cannot receive water vapor coming from the evaporation of the liquid film. Therefore, the evaporated mass flow rate decreases.

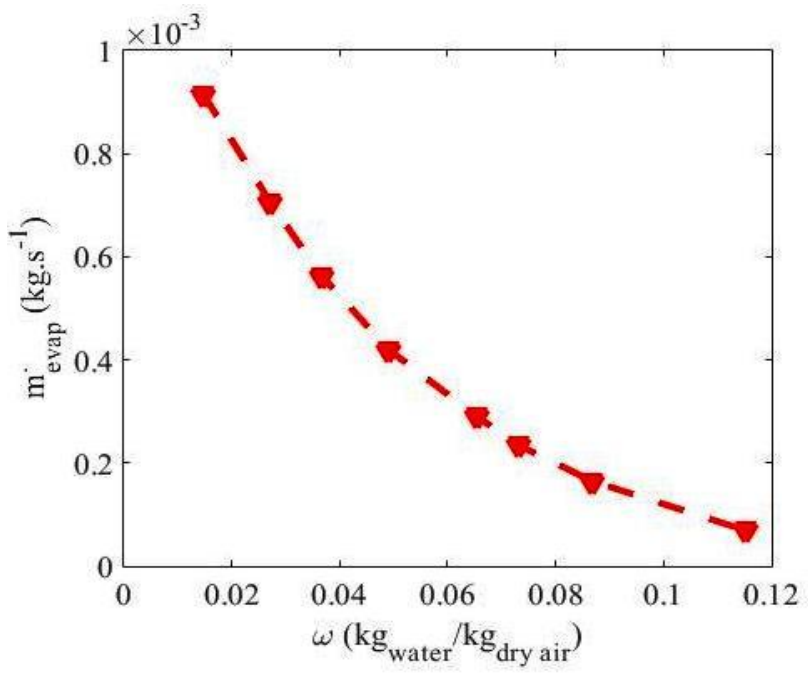

Fig. 8 Evolution of the evaporated mass flow rate according to the inlet air humidity in the humidifier. $\left(T_{f-h u m, 0}=30^{\circ} \mathrm{C}, \dot{m}_{f, 0}=\right.$ $0.001528, \quad T_{a, L}=35^{\circ} \mathrm{C}, \dot{m}_{a}=0,0147 \mathrm{~kg} . \mathrm{s}^{-1} 1, T e \_0=20^{\circ} \mathrm{C}$, $\dot{m}_{w}=0.035 \mathrm{~kg} . \mathrm{s}^{-1}$ )

\section{Conclusion}

In this work, a numerical study of a solar desalination system by humidification-dehumidification was realized. This unit consists of a humidifier and a dehumidifier. The numerical study was based on the resolution of Heat and mass balances at the level of each system component. In order to validate the mathematical model, a comparison between numerical and experimental results is conducted. The work consists essentially of a parametric study to improve of the desalination unit production installed at the faculty of sciences of Bizerte, Tunisia. The influence of mass flow rate and temperature of the feed water as well as the temperature and humidity of the air in the humidifier on evaporated and condensed mass flow rates is studied. The obtained results then show that the evaporated and condensed mass flow rates in the solar desalination unit increase with the feed water and air temperatures in the humidifier. It should be noted that evaporated and condensed mass flow rates of this desalination system increase to reach their maximum values which correspond to a feed water mass flow rate of the order of $5.51 / \mathrm{h}$. Then these two mass flow rates decrease with the increase of the feed water mass flow rate. 


\section{Nomenclature}

$\mathrm{C}_{\mathrm{p}}:$ Specific heat capacity $\left(\mathrm{J} \cdot \mathrm{Kg}^{-1} \cdot \mathrm{K}^{-1}\right)$

d: Diameter $(\mathrm{m})$

G: Solar irradiation $\left(W . \mathrm{m}^{-2}\right)$

$\mathrm{h}$ : Heat transfer coefficient $\left(\mathrm{W} / \mathrm{m}^{2} . \mathrm{K}\right)$

$\mathrm{h}^{\prime}$ : Total heat transfer coefficient between the liquid film and the gas phase in the humidifier

$\mathrm{H}$ : humidity (\%)

$\mathrm{h}_{\mathrm{m}}$ : Mass transfer coefficient $\left(\mathrm{Kg} / \mathrm{m}^{2} . \mathrm{s}\right)$

1: Width (m)

L: Length $(\mathrm{m})$

$\mathrm{L}_{\mathrm{v}}$ : Latent heat of evaporation $\left(\mathrm{J} \cdot \mathrm{Kg}^{-1}\right)$

$\dot{\mathrm{m}}$ : Mass flow rate $\left(\mathrm{kg} . \mathrm{s}^{-1}\right)$

$\mathrm{N}$ : Condenser tubes number

S: Surface $\left(\mathrm{m}^{2}\right)$

$\mathrm{T}$ : Température $(\mathrm{k})$

$\mathrm{X}$ : Position (m)

$\mathrm{V}$ : Velocity $\left(\mathrm{m} \cdot \mathrm{s}^{-1}\right)$

Greek letters

$\alpha$ : Absorptivity

$\alpha_{\mathrm{t}}$ : Fictive absorption coefficient of the liquid film

$\tau$ : Transmissivity

$\rho$ : Reflectivity

$\omega$ : Specific humidity $\left(\mathrm{kg}_{\text {water }} / \mathrm{kg}_{\text {dry air }}\right)$

$\sigma$ : Constant of Stefan-Boltzmann $\left(\mathrm{W} \cdot \mathrm{m}^{-2} \cdot \mathrm{K}^{-4}\right)$

$\varepsilon$ : Emissivity

$\theta$ : Angle of inclination of the humidifier $\left(^{\circ}\right)$

Indices

a: Air

amb : Ambient

aver: Average

c: Condensat

cond: Condensation

deh: Dehumidifier

eff: Effectif

evap: Evaporated

ext: Outside

f: Film

g: Gas

ha : Humid air

hum : Humidifier

int: Inside

$\mathrm{p}$ : Plate

sat: Saturation

t: Tube

v: Glass

va : Vapor

w: Water

Acronymes

$\mathrm{CN}$ : Natural convection

CF: Forced convection

HDH: Humidification-dehumidification

\section{References}

1. E.E. Delyannis, V. Belessiotis, Desalination, 10027 (1995).

2. M. Bessenasse, A. Kettab, A. S.Moulla, Seawater desalination, Desalination, 250423 (2010).

3. A. Kettab, Desalination, 13625 (2001).

4. J. Orfi, M. Laplante, H. Marmouch, N. Galanis, B. Benhamou, S. Ben Nasrallah , C.T. Nguyen, Desalination, 168151 (2004).

5. G. Al-Enezi, H. Ettouney, N. Fawzy, Energy Convers. Manag., 47470 (2006).

6. G. Yuan, H. Zhang, Desalination, 205156 (2007).

7. C. Yamale, I. Solmus, Desalination, 220538 (2008).

8. S.M. Soufari, M. Zamen, M. Amidpour, Desalination Water Treat., 6244 (2009)

9. S. Farsad, A. Behzadmehr, S.M. Hosseini Sarvari, Desalination Water Treat., 19294 (2010).

10. K. Zhani, H. Ben Bacha, Energy, 352610 (2010).

11. S. Saidi, R. Ben Radhia, B.Dhifaoui, S. Ben Jabrallah, Desalination Water Treat., 562576 (2014). 